\title{
REALITIES: THE VIEWS OF SCIENTISTS
}

\author{
Mohira Umarova \\ PhD Student, Tashkent State University of Oriental Studies, Tashkent, Uzbekistan
}

Shakhnoza Yakubova
Senior Lecturer, Tashkent State University of Oriental Studies, Tashkent, Uzbekistan

Article DOI: https://doi.org/10.36713/epra4670

\begin{abstract}
This article defines the term "reality" as the functionality of words in this particular category as components necessary to convey the national identity of texts in different languages.

Summarizing the experience of foreign linguists, the authors come to the conclusion that realities are lexical units that name unique objects and phenomena characteristic of life, everyday life, culture, social and historical development of one people and alien to another people, that is, they are the verbal expression of specific features of national cultures. Realities do not have clear correspondence in another language and require a special approach in translation.

The authors of the article conclude that there is currently no single approach to classifying facts, as in the definition of the concept. The basic principle of all existing classifications of facts is the method of grouping realities according to a thematic principle.
\end{abstract}

KEYWORDS: reality, linguistic, non-equivalent vocabulary, Acquaintances (vocabulary), object, concept, phenomenon.

\section{INTRODUCTION}

In the process of translating a work of fiction, the translator must not only adequately convey the original text, preserving its content, emotional-expressive and aesthetic value, but also express the socio-cultural and national flavor. The translated work has its own special artistic value, which the translator must convey. Achieving this goal is hard work, one of the sides of which is the translation of realities. They are familiar and familiar to native speakers, but readers of a translated work may not understand what is at stake. This means that the translator must not only find and correctly understand the realities in the text, but also carry out the translation in such a way that the representative of the foreign language culture understands what the text is about.
The main task of a literary text translator is to create a work of artistic value equal to the original. The works of art have a lot of non-equivalent vocabulary that serves to create a national color, but in fact show semantic shadows that create a linguistic picture of the world of a particular nation, so the main task of the translator is to preserve the linguistic picture of the original work is to recreate the text.

\section{THE MAIN FINDINGS AND RESULTS}

Thus, in various dictionaries, realities are considered either as words, or as an object, concept or phenomenon. The same inconsistency is observed in the use of this concept in the works of various linguistic scientists: researchers call reality either an object, a concept, a phenomenon characteristic of the history, culture, way of life, way of life of one or another people of the country, which is not found 


\section{EPRA International Journal of Research and Development (IJRD)}

among other peoples; or a word denoting such an object, concept, phenomenon, also a phrase (phraseological unit, proverb, proverb) that includes such words.

Subsequently, different linguists differently designated this phenomenon: the terms "barbarism" (A.A. Reformatsky), "exoticism" (V.P. Berkov), "exotic vocabulary" (A.E. Suprun, G.V. Chernov), "Non-equivalent vocabulary" (AV Fedorov, E.M Vereshchagin, V.G Kostomarov, Ya.I. Retsker, A.D Schweitzer etc.) At the same time, disagreements are observed not only in the definition of the concept, but also in the sense that various authors put into the concept. Before comparing some of the existing classifications of realities in Russian linguistics, we want to compare the definitions of the term "reality" given by researchers who have worked on this problem.

There is a huge variety of realities, each of which is characterized by a certain form, lexical, phonetic and morphological features. Naturally, linguists were faced with the question of their ordering, i.e. it became necessary to implement the classification of realities, which, firstly, would characterize this specific vocabulary, and secondly, would contribute to a more accurate translation of realities from one language to another.

N.A. Fenenko, while agreeing with the term "reality", nevertheless speaks of its "terminological insufficiency, since it designates the phenomenon of extra-linguistic reality (subject), and its cultural equivalent (concept), and the means of nominating this concept in language" ... Realizing what difficulties are created by the constant need to clarify the semantic connotation of the term in each individual case, A. A. Kretov and N. A. Fenenko have developed a linguistic theory of reality. In continuation of the idea of the semantic triad "subject - concept - word", a three-part system of terms was introduced: 1. Reality as an object of reality (natural fact, artifact) - R-reality. 2. Reality as an ideal equivalent of the environment of society (concept) C-reality. 3. Reality as a means of nomination of a cultural concept - L-reality. Summarizing the above points of view, we can come to the conclusion that there is no unambiguous interpretation of the concept of "reality". Some researchers give too broad interpretations, others - too concise, using different terms to denote realities. The approach of S. Vlakhov and S. Florin (1980) is the closest to us in defining the concept of "reality", which we will be guided by in our further research.

In order for such a division to acquire real content, the authors consider the following issues, conditioned by the factor of time: 1) the connection of realities in the subject and time; 2) by place and time; 3) the entry of foreign realities into the language; 4) one of the main ways of such admission is through fiction and 5) the question of familiarity / unfamiliarity of realities, closely related to the use of realities in general and the development of other people's realities.

Depending on the degree of development, the realities are divided into:

1. Acquaintances (vocabulary);

2. Unfamiliar (non-dictionary);

Fashionable and episodic realities are closely connected with them. Fashionable ones capture the attention of wide circles of society, primarily young people, and are usually soon forgotten. Episodic realities are extra-dictionary realities. Authors and translators "enter them, depending on the requirements of the context, once or several times, in a word, episodically, but they do not receive distribution, are not fixed in the language, and, therefore, do not get into dictionaries"

So, the classification of S. Vlakhov and S. Florin is based on several principles. The authors take into account both the thematic principle and the principle of local division (in the plane of one or several languages) and the principles of time division.

\section{CONCLUSION}

In the definition of the term "reality", summarizing the experience of linguists who considered realities, we emphasize the following features of this layer of vocabulary:

1. Realities are lexical units that name unique objects and phenomena characteristic of the life, everyday life, culture, social and historical development of one people and alien to another people, that is, they are a verbal expression of the specific features of national cultures.

2. Realities intersect with non-equivalent vocabulary: untapped realities are part of this layer of vocabulary, and mastered vocabulary realities are not included in it.

3. Realities do not have exact correspondences in another language and require a special approach in translation.

4. This group of vocabulary is characterized by flexibility: without losing their status, they can simultaneously belong to several lexical categories, that is, the same word can be both a term and a proper name, while remaining a reality.

Modern linguistics has not developed a single classification of realities. Some researchers do not use the term reality, preferring the term nonequivalent dictionary or background data, while others distinguish realities as a layer of nonequivalent vocabulary and suggest their own classifications.

The former include V.S. Vinogradov, A.V. Fedorov, G.D. Tomakhin, M.L. Vaysburg, A.D. Schweitser and other researchers. Realities as a word 


\section{EPRA International Journal of Research and Development (IJRD)}

denoting an unfamiliar concept from the translated language were considered by L.N. Sobolev, V.1. Rossels, A.E. Suprun, L.S. Barkhudarov, Ya.I. Retsker.

V.S. Vinogradov calls realities all the specific facts of the history and state structure of a national community, the features of its geographical environment, typical household items of the past and present, ethnographic and folklore concepts, referring them to the class of non-equivalent vocabulary.

Just as in the definition of a concept, there is no single approach to the classification of realities. The main principle of all available classifications of realities is a way of grouping realities according to thematic principle. In our study, the classifications of realities proposed by G.D. Tomakhin, E.M. Vereshchagin and V.G. Kostomarov, L.S. Barkhudarov, V.S. Vinogradov, S. Vlakhov and S. Florin.

G.D. Tomakhin identifies modern and historical realities, identifies 3 large groups: onomastic realities; realities indicated by appellative lexicon; realities of the aphoristic level.

E.M. Vereshchagin and V.G. Kostomarov singled out seven groups of words that have national and cultural semantics: Sovietisms, words of a new way of life, words of traditional life, historicism, phraseological units and words from folklore and words of non-Russian origin.

L.S.Barkhudarov distinguishes the following categories: proper names, geographical names, names of institutions, organizations, newspapers, etc. realities-words denoting objects, concepts and situations that do not exist in the practical experience of people speaking another language; random gaps vocabulary units of one of the languages, which for some reason do not correspond in the lexical composition of the target language.

V.S. Vinogradov divides all words-realities into 6 groups, highlighting: vocabulary calling everyday realities; ethnographic and mythological realities; vocabulary calling the realities of the natural world; the realities of the state and administrative structure and social life; vocabulary calling onomastic realities; and, finally, vocabulary that reflects associative realities. The researcher examines and systematizes the stock of lexical units that deliver background information, and assumes that the classification given by him is apparently incomplete.

\section{REFERENCES}

1. Weisburd M.L. Realities as an element of regional studies / M.L. Weissburd // Rus. lang. abroad. 1972. No. 3. - p. 98.

2. Schweitzer $A D$ Translation and linguistics. Moscow: Voenizdat, 1973.-p. 250

3. Rossels V.l. On the transfer of the national form in fiction (Notes of the translator). Moscow: 1953. p. 169

4. Suprun AE Exotic vocabulary. FN, Moscow: 1958, No. 2, -pp. 50-54

5. Barkhudarov L.S. Language and translation / L.S. Barkhudarov. Moscow: International Relations, 1975. - p.95

6. Kretov A. A. Linguistic theory of reality // A. A. Kretov; N. A. Fenenko. Voronezh Bulletin. state un-that. Ser: Linguistics and intercultural communication. 2013. No. 1. - pp. 7-13.

7. Vereshchagin E.M; Kostomarov V.G. Language and culture. Ed. 2nd. Moscow: Russian language, 1976.-p. 28

8. Untranslatable in translation / S. Vlakhov, S. Florin. Moscow: International Relations, 1980. pp. 47-54.

9. Vasilyeva N.V. A short dictionary of linguistic terms. Moscow: 1995.

10. Vinogradov, V.S. Lexical issues of translation of literary prose. Moscow: Publishing house of Moscow University, 1978. - p. 172.

11. Omonov, Q., \& Karimov, N. (2020). Importance Of Ancestoral Heritage. The American Journal of Social Science and Education Innovations, 2(09), 196-202.

12. https://www.gramota.net/materials/1/2010/32/48.html

13. https://www.dissercat.com/content/priemyperedachi-russkikh-realii-v-nemetskikhperevodakh-romanov-fm-dostoevskogo

14. https://www.dissercat.com/content/otrazhenierealii-russkoi-kultury-v-angliiskikh- $i$ frantsuzskikh-perevodakh-na-materiale-roma 